\title{
Lack of Relationship between Testicular Echotexture and Seminal Characteristics in Adult Texel Rams
}

\author{
Mariana A. G. Urt, Edwin W. B. Bakarji, Fábio J. C. Faria, Elisvânia F. Santos, Deiler S. Costa* \\ Federal University of Mato Grosso do Sul, Campo Grande, Brazil \\ Email: ^deiler.costa@outlook.com
}

How to cite this paper: Urt, M.A.G., Bakarji, E.W.B., Faria, F.J.C., Santos, E.F. and Costa, D.S. (2018) Lack of Relationship between Testicular Echotexture and Seminal Characteristics in Adult Texel Rams. Agricultural Sciences, 9, 936-946. https://doi.org/10.4236/as.2018.98065

Received: July 14, 2018

Accepted: August 7, 2018

Published: August 10, 2018

Copyright ( 92018 by authors and Scientific Research Publishing Inc. This work is licensed under the Creative Commons Attribution International License (CC BY 4.0).

http://creativecommons.org/licenses/by/4.0/

\begin{abstract}
The objective of this study was to determine the minimum representative area to evaluate testicular echotexture parenchyma and to identify the correlations between the intensity of pixels of the testicular parenchyma and the fibrosis score with the physical and morphological characteristics of the ejaculate of Texel rams. The study used 88 Texel rams, aged between 10 and 12 months, and reared in a semi-extensive system. The animals underwent breeding soundness evaluation (BSE) and ultrasound of the testicles. The images were transferred to a computer where they were defined in areas of 400 , 1600,3600 , and $6400 \mathrm{~mm}^{2}$, after which the average intensity of the pixels of each image of the testicular regions was evaluated. A testicular fibrosis score was assigned in order to quantify the frequency of fibrotic lesions. In relation to the intensity of pixels of the predetermined regions, only the area of 400 $\mathrm{mm}^{2}$ presented a difference $(\mathrm{P}<0.05)$, with the area of $1600 \mathrm{~mm}^{2}$ being the smallest area that best represented the testicular parenchyma. There were no correlations between the intensity of pixels of the testicular parenchyma and the fibrosis score with the physical and morphological characteristics of the ejaculate of the rams.
\end{abstract}

\section{Keywords}

Ovine, Breeding Soundness Evaluation, Testicular Ultrasound

\section{Introduction}

The first reports of ultrasound application in veterinary medicine emerged in 1966, in the diagnosis of pregnancy in ewes. Since then, improvements in the quality of equipment, combined with the growing acceptance of the benefits of 
the technique have led to a diversified use of ultrasonography in veterinary medicine [1]. In the mid-80s, the use of ultrasonography for the evaluation of soft tissues in several animal species revolutionized research in animal breeding, improving the knowledge of gonadal structure and function and of the pathology of genital organs, and allowing a better understanding of the reproductive physiology. According to Ginther [2], ultrasonographic diagnosis constituted the biggest technological advancement in large animal and clinical reproduction research since the introduction of rectal palpation and radioimmunoassay for the analysis of hormones.

Computational analysis of the attributes of images is a natural extension of the advances in ultrasonographic diagnosis. This technique is based on the identification, and frame by frame (pixel by pixel), and of the intensity of the return of the ultrasonographic wave. Each pixel that forms the image represents a discrete reflection of the tissue and can assume one of the 256 tones of the gray scale, ranging from completely black (0) to completely white (255) [3]. In turn, the combination of thousands of pixels forms an image. The density and the tissue characteristics can be observed via ultrasound, but not quantified by the human eye. Visually, one can distinguish only 18 to 20 tones of gray, which leads to different individual perceptions and, consequently, variations in image interpretation [4]. Computational analysis can reveal differences in echotexture imperceptible to the human eye, and allows measurements of such differences in a very objective way, by the establishment of computer algorithms. Such algorithms have been developed specifically for ultrasound image analyses in order to reduce the subjectivity of visual assessment and to quantify the values of each pixel of the image [5].

The objective of this research was to determine the minimum representative area to evaluate the echotexture of the testicular parenchyma and to identify the correlations between the intensity of pixels of the testicular parenchyma and the fibrosis score with the physical and morphological characteristics of the ejaculate of Texel rams.

\section{Materials and Methods}

The study used 88 young rams of the Texel breed, aged between 10 and 12 months. The animals came from a farm located in the municipality of Nova Andradina, MS, Brazil (latitude $21^{\circ} 56^{\prime} 40^{\prime \prime S}$ and longitude 53 $33^{\prime} 10^{\prime \prime} \mathrm{W}$; average annual temperature, $28^{\circ} \mathrm{C}$; pluviometric precipitation, $1650 \mathrm{~mm}$ ). The sheep were maintained using a semi-extensive regime, in predominantly pasture grass (Brachiaria humidicola), receiving mineral salt and water ad libitum and supplemented with corn silage until the time of breeding soundness evaluation (BSE). The experiment was carried out during the month of August/2017.

After individual containment of the animals, they were evaluated and classified according to the body condition score (BCS) and scrotal circumference (SC) measurement. The evaluation of the BCS was carried out by palpation of the 
muscular and adipose tissues covering the lumbar region of the animals, using a scale from 0 to 5 points (from very thin to very fat), as proposed by Jefferies [6]. Animals with BCS below 2.5 were not used. Ultrasound images of the testicular parenchyma were obtained in longitudinal planes, on the caudal side of the testicles with the aid of a Mindray device (DP2200 VET), coupled to a $7.5 \mathrm{MHz}$ linear transducer, with the use of acoustic gel on the scrotum. A single image of the right and left testicle was obtained for each animal.

All obtained images were transferred to a computer and analyzed with the aid of ImageJ software, capturing the average intensity of pixels (IP) on a scale ranging from 0 (totally black) to 255 (totally white). To define the smallest representative area of pixels, the images of the testicles were delimited to regions with square measurements of $20 \times 20,40 \times 40,60 \times 60$, and $80 \times 80 \mathrm{~mm}$, corresponding to $400,1600,3600$, and $6400 \mathrm{~mm}^{2}$ areas.

Analyses of the testicles were carried out by examining a predetermined region in each image of the right and left testicles. It was considered that the regions measured in the images only comprised the testicular parenchyma. A fixed value for the proximal and distal gain was predetermined for all the tests in order to standardize the ultrasound assessments and to allow comparison between them.

The evaluation of the fibrosis score and/or testicular calcification was performed by means of lateral positioning of the transducer in the middle region of each testicle, making up a complete scan of testicular parenchyma of approximately $45^{\circ}$ and assigning a score from 0 to 6 in order to quantify the fibrotic lesions, as recommended by Pinho et al. [7]: 1) no fibrosis point observed in the testicular parenchyma, 2) 1 to 10 fibrosis points spread around the testicular parenchyma, 3) 11 to 30 fibrosis points spread around the testicular parenchyma, 4) 31 to 50 fibrosis points spread around the testicular parenchyma, 5) 51 to 100 fibrosis points spread around the testicular parenchyma, 6) more than 100 fibrosis points spread around the testicular parenchyma, and 7) areas of fibrosis in various forms accompanied by fibrosis points.

The ejaculate was collected, immediately after the ultrasound examination, by the electro-ejaculation method. The evaluation of physical and morphological evaluations the semen were performed according Brazilian College of Animal Reproduction (CBRA) [8]. For the interpretation of the and urological tests, were the classification for ovines advocated by the CBRA was used, in which the reproductive potential is predicted through the physical and morphological characteristics of the semen, as follows: progressive spermatic motility (70\%), major sperm defects $(<10 \%)$, minor spermatic defects $(<20 \%)$, and total spermatic defects ( $<30 \%$ of the total anomalies). In this way, all study animals had previously undergone BSE and were subsequently subdivided into two groups of and urological classes, as follows: 1) able to reproduction, and 2) unable to reproduction.

All international guidelines for the care and use of animals for scientific purposes were followed in this experiment. 
In order to determine the representative minimum area of echotexture of the testicular parenchyma, the variable average value of the pixels in each area was tested for normality verification (Lilliefors test) and homogeneity of variances (Cochran's and Bartlett's tests). Following this determination, analysis of variance (ANOVA) was applied, and the respective averages of the evaluated areas were compared using Tukey's test with a 5\% significance level. To determine the homogeneity of the echotexture of the testicular parenchyma between the right and left testicles and between different areas of the same testicles, pixel values measured in three different regions of each testicle of the same animal were also tested to verify normality. Following this determination, ANOVA was performed. The values obtained allowed testing of whether there existed differences in the echotexture between different areas of the same testicle and between the bilateral testicles. The averages value of the pixels measured in three different regions of each testicle were compared by Tukey's test, while the averages between the right and left testicles were compared using the t-test. The significance level adopted was $5 \%$. The verification of possible correlations between the echotexture of testicular parenchyma and seminal parameters was performed by Pearson's correlation.

\section{Results}

According to the intensity of pixels, the normal ram testicle was homogeneous and moderately echogenic (Figure 1). Regarding the intensity of the pixels of the predetermined regions (Table 1), there was a difference between the testicles in the area of $400 \mathrm{~mm}^{2}(\mathrm{P}<0.05)$, while the other tested areas showed no pixel intensity difference between the testicles. Thus, it was decided to use the average IP of the left and right testicles of the $1600 \mathrm{~mm}^{2}$ area in the following analyses (Tables 2-4), with this area being the smallest area that best represented the testicular parenchyma.

No correlation was found between the average intensity of the pixels of the $1600 \mathrm{~mm}^{2}$ area with the average physical and morphological parameters of the ejaculate and, consequently, the reproductive capacity of the rams (Table 2).

Table 1. Intensity of pixels (IP) in accordance with the representative area of the predetermined testicular regions.

\begin{tabular}{cccc}
\hline Predetermined region $\left(\mathrm{mm}^{2}\right)$ & IP LT & IP RT & Average IP \\
\hline 400 & $104.8^{\mathrm{Ba}}$ & $113.0^{\mathrm{Ab}}$ & 108.9 \\
1600 & $107.7^{\mathrm{Aa}}$ & $111.3^{\mathrm{Aa}}$ & 109.5 \\
3600 & $101.2^{\mathrm{Ba}}$ & $105.9^{\mathrm{Ba}}$ & 103.6 \\
6400 & $97.0^{\mathrm{Ca}}$ & $101.5^{\mathrm{Ca}}$ & 99.3 \\
\hline
\end{tabular}

${ }^{a, b}=$ average values, followed by different small letters on the same line, differ between each other by Tukey's test $(P<0.05),{ }^{A, B}=$ average values of the same parameter, followed by capital letters in the same column, differ between each other by Tukey's test $(\mathrm{P}<0.05) . \mathrm{LT}=$ left testicle, $\mathrm{RT}=$ right testicle. ${ }^{*}$ Average of the left and right testicles. 


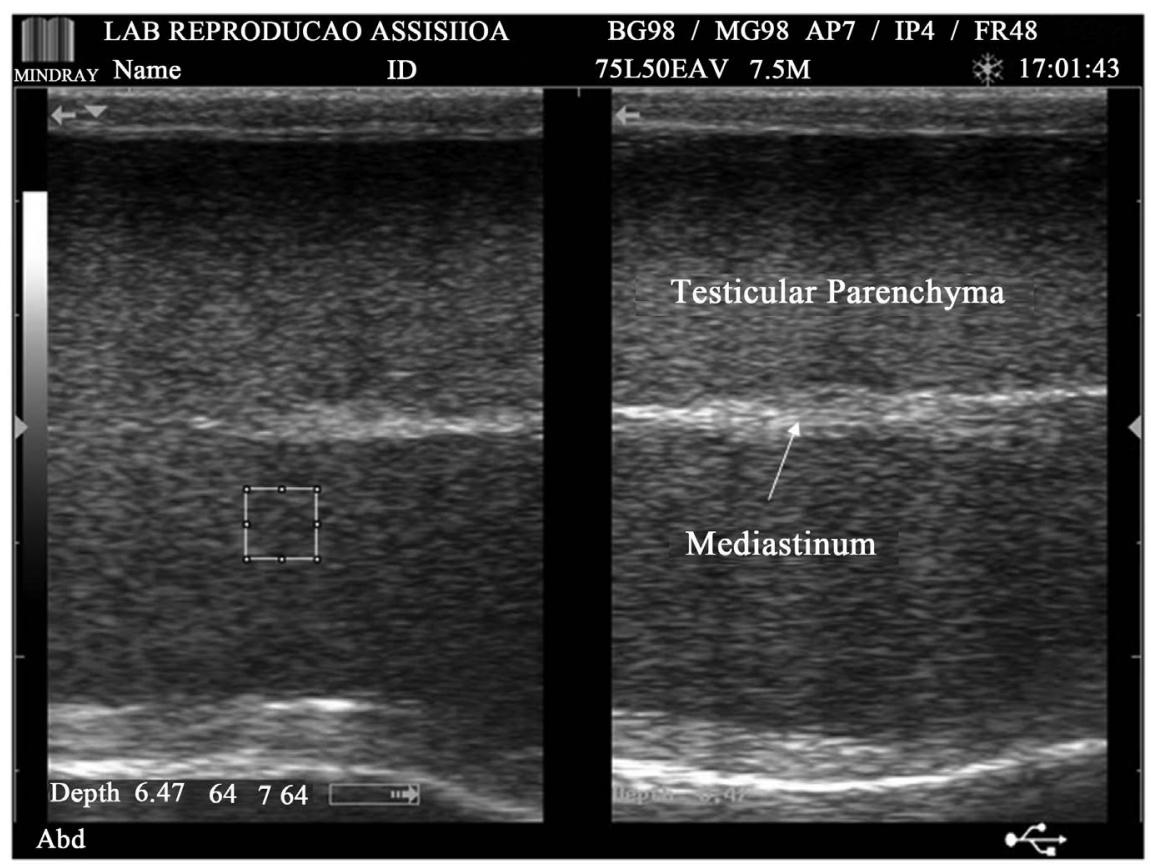

Figure 1. Ultrasound images of the testicular parenchyma and mediastinum of Texel rams. Square area $=1600 \mathrm{~mm}^{2}$.

Table 2. Correlations between the average intensity of pixels in the area of $1600 \mathrm{~mm}^{2}$ and quality parameters of the ejaculate of Texel rams.

\begin{tabular}{ccc}
\hline Parameters & Mean \pm SD & Correlations \\
\hline MOT (\%) & $70.39 \pm 18.36$ & $0.04^{\mathrm{NS}}$ \\
VIG (0 - 5) & $3.48 \pm 0.90$ & $0.03^{\mathrm{NS}}$ \\
MDEF (\%) & $5.73 \pm 11.59$ & $-0.02^{\mathrm{NS}}$ \\
MINDEF (\%) & $5.31 \pm 11.93$ & $0.06^{\mathrm{NS}}$ \\
TDEF (\%) & $11.04 \pm 18.91$ & $0.03^{\mathrm{NS}}$ \\
\hline
\end{tabular}

$\mathrm{MOT}=$ straight-line progressive spermatic motility; VIG $=$ spermatozoon vigor; $\mathrm{MDEF}=\%$ of major defects; $\mathrm{MINDEF}=\%$ of minor defects; $\mathrm{TDEF}=\%$ of total defects; $\mathrm{SD}=$ standard deviation; ${ }^{\mathrm{NS}}=$ no significant correlation.

Table 3. Number of Texel rams with fibrotic lesions in the testis.

\begin{tabular}{cc}
\hline Parameters & $\mathrm{n}$ \\
\hline Number of evaluated rams & 88 \\
Not show fibrotic lesions & 56 \\
Showed fibrotic lesions & 32 \\
Had lesions in both testicles & $16 / 32$ \\
Had lesions only in the right testicle & $8 / 32$ \\
Had lesions only in the left testicle & $8 / 32$ \\
\hline
\end{tabular}


Table 4. Correlations of the fibrosis score of the right testicle, age, testicular consistency and physical and morphological parameters of the ejaculate.

\begin{tabular}{|c|c|c|c|c|c|c|c|c|}
\hline & \multicolumn{8}{|c|}{ Pearson correlation } \\
\hline & FPSRT & AGE & TURB & MOT & VIG & MDEF & MINDEF & TDEF \\
\hline FSRT & 1 & $0.61^{* *}$ & $-0.01^{\mathrm{NS}}$ & $0.11^{\mathrm{NS}}$ & $0.08^{\mathrm{NS}}$ & $-0.10^{\mathrm{NS}}$ & $-0.12^{\mathrm{NS}}$ & $-0.14^{\mathrm{NS}}$ \\
\hline AGE & & 1 & $-0.09^{\mathrm{NS}}$ & $-0.20^{\mathrm{NS}}$ & $0.16^{\mathrm{NS}}$ & $-0.11^{\mathrm{NS}}$ & $0.03^{\mathrm{NS}}$ & $-0.04^{\mathrm{NS}}$ \\
\hline TURB & & & 1 & $0.82^{* *}$ & $0.85^{* *}$ & $-0.12^{\mathrm{NS}}$ & $-0.06^{\mathrm{NS}}$ & $-0.11^{\mathrm{NS}}$ \\
\hline MOT & & & & 1 & $0.91^{* *}$ & $-0.08^{\mathrm{NS}}$ & $-0.02^{\mathrm{NS}}$ & $-0.06^{\mathrm{NS}}$ \\
\hline VIG & & & & & 1 & $-0.13^{\mathrm{NS}}$ & $-0.09^{\mathrm{NS}}$ & $-0.14^{\mathrm{NS}}$ \\
\hline MDEF & & & & & & 1 & $0.29^{*}$ & $0.79^{* *}$ \\
\hline MINDEF & & & & & & & 1 & $0.81^{* *}$ \\
\hline TDEF & & & & & & & & 1 \\
\hline
\end{tabular}

FSRT = fibrosis score of the right testicle; CONS = consistency; TURB = turbulence; MOT = spermatic motility; VIG = spermatic vigor; $\mathrm{MDEF}=$ major defects; $\mathrm{MINDEF}=$ minor defects; $\mathrm{TDEF}=$ total defects. ${ }^{*}$ Correlation is significant at a level of 0.01 . ${ }^{\star}$ Correlation is significant at a level of 0.05 . NS $=$ no significant correlation.

The number of animals with fibrotic lesions in the testis is presented in Table 3. Among the animals that had fibrosis in both testicles, $81 \%$ had scores of $1 / 1$, $13 \%$ scores of $1 / 2$, and $6 \%$ scores of $2 / 1$, for the left/right testicles, respectively.

No correlations were found between the fibrosis score and the physical and morphological parameters of the semen (Table 4 and Table 5).

A total of $85 \%(75 / 88)$ of the animals were classified as being able to reproduction, while $15 \%(13 / 88)$ were deemed unable to reproduction. The results of the testicular echotexture of the left and right testicles, and the average of the two testicles, according to these two subgroups, are summarized in Table 6. There was no difference in the IP of the studied testicular images $(\mathrm{P}>0.05)$ between able and unable animals.

As expected, the evaluated parameters were considered the most optimal in animals classified as able to reproduce, showing a difference only in motility and spermatic vigor between the two classes $(\mathrm{P}<0.05)$.

\section{Discussion}

In the scientific literature, apart from the present study, there is no previous report regarding testicular echotexture of rams of the Texel breed, with research on hair sheep, particularly the Santa Inês breed, being the most widespread. Jucá et al. [9] characterized the echotexture of the testicles of young ovines in the phase of testicular maturation by assessing Santa Inês rams at weaning. They found no differences in echogenicity in the evaluations of the parenchyma and calcifications between the right and left testicles, classifying $90.24 \%$ of the images as hypoechoic with low-intensity (IP 111) and 9.76\% as hypoechoic with high intensity (IP 12), and correlating these findings with the ages of the animals. Andrade et al. [10] demonstrated homogeneous testicular parenchyma, with the 
Table 5. Correlations of the fibrosis score of the left testicle, age, and physical and morphological parameters of the ejaculate.

\begin{tabular}{ccccccccc}
\hline & \multicolumn{7}{c}{ Pearson Correlation } \\
\cline { 2 - 8 } & FSLT & AGE & TURB & MOT & VIG & MDEF & MINDEF & TDEF \\
\hline FSLT & 1 & $0.47^{* *}$ & $-0.21^{\mathrm{NS}}$ & $0.22^{\mathrm{NS}}$ & $0.17^{\mathrm{NS}}$ & $-0.04^{\mathrm{NS}}$ & $-0.09^{\mathrm{NS}}$ & $-0.08^{\mathrm{NS}}$ \\
AGE & & 1 & $-0.09^{\mathrm{NS}}$ & $-0.20^{\mathrm{NS}}$ & $0.16^{\mathrm{NS}}$ & $-0.11^{\mathrm{NS}}$ & $0.03^{\mathrm{NS}}$ & $-0.04^{\mathrm{NS}}$ \\
TURB & & & 1 & $0.82^{* *}$ & $0.85^{* *}$ & $-0.12^{\mathrm{NS}}$ & $-0.06^{\mathrm{NS}}$ & $-0.11^{\mathrm{NS}}$ \\
MOT & & & 1 & $0.91^{* *}$ & $-0.08^{\mathrm{NS}}$ & $-0.02^{\mathrm{NS}}$ & $-0.06^{\mathrm{NS}}$ \\
VIG & & & & & 1 & $-0.13^{\mathrm{NS}}$ & $-0.09^{\mathrm{NS}}$ & $-0.14^{\mathrm{NS}}$ \\
MDEF & & & & & & 1 & $0.29^{*}$ & $0.79^{* *}$ \\
MINDEF & & & & & & & 1 & $0.81^{* *}$ \\
TDEF & & & & & & & & 1 \\
\hline
\end{tabular}

FSLT = fibrosis score of the left testicle; CONS = consistency; TURB $=$ turbulence; MOT $=$ straight-line progressive spermatic motility; VIG = spermatic vigor; $\mathrm{MDEF}=$ major defects; $\mathrm{MINDEF}=$ minor defects; TDEF $=$ total defects. ${ }^{* *}$ Correlation is significant at a level of $0.01 .{ }^{*}$ Correlation is significant at a level of $0.05 .{ }^{\mathrm{NS}}=$ no significant correlation.

Table 6. Intensity of pixels of the testicles of Texel rams, classified as able and unable to reproduction.

\begin{tabular}{ccc}
\hline Parameters & Able & Unable \\
\hline Left testicle & $108.0^{\mathrm{aA}}$ & $105.9^{\mathrm{aA}}$ \\
Right testicle & $111.9^{\mathrm{aA}}$ & $114.0^{\mathrm{aA}}$ \\
Average of the two testicles & $109.95^{\mathrm{aA}}$ & $109.95^{\mathrm{aA}}$
\end{tabular}

${ }^{\mathrm{a}, \mathrm{b}}=$ average values, followed by different small letters on the same line, differ between each other by Tukey's test $(\mathrm{P}<0.05) .{ }^{\mathrm{A}, \mathrm{B}}=$ average values of the same parameter, followed by capital letters in the same column, differ between each other by Tukey's test $(\mathrm{P}<0.05)$.

echogenicity ranging from low to moderate, regardless of the testicle (right or left) and the scanning plane used. Instead, they found that the echogenicity increased in direct proportion to the age of the animals, corroborating the results of Cartee et al. [11], and Moura et al. [12].

A similar result was observed in the present study, in which the average intensities of the pixels according to the representative area of the predetermined testicular regions on the ultrasound images, were found to be moderately echogenic relative to the gray scale used $(0-255)$. This result may be related to the stage of sexual maturity of the rams studied (end of puberty and beginning of sexual maturity), and the anatomical changes of the seminiferous tubules, which, according to Aravindakshan et al. [13], and Hamm and Fobbe [14], become longer and twisted, increasing in diameter, and forming the lumen [14], as a result of the increased thickness of the basement membrane during this period. This suggests the possibility of using ultrasonography to monitor the progressive changes that occur in the testicles [7], as well as the homogeneity of the lot.

Based on this knowledge and the fact that no correlation was found between the seminal characteristics and the IP values of the studied images, Arteaga et al. 
[15] stated that testicular ultrasonography is better associated with future seminal patterns than with the characteristics of the semen at the time of ultrasound evaluation. However, this finding is likely due to the lack of correlation found by these authors between testicular echotexture and seminal characteristics, since they only observed the IP correlation with seminal characteristics from two to four weeks after the ultrasound examination, and not with the seminal characteristics at the time of ultrasound evaluation.

Regarding the identification of testicular alterations, there was no correlation between the degree of testicular impairment and the observed fibrosis score with the seminal characteristics $(P>0.05)$ of the rams in the present study. However, significant correlations were observed between the fibrosis score and age $(\mathrm{P}<$ 0.01).

Barth et al. [16] observed no difference in the fibrosis score between the left and right testicles. These same authors, when evaluating 175 bulls (Bos taurus taurus), aged between 10 and 12 months old, observed that $70 \%$ presented some testicular fibrosis impairment; of these, $15.4 \%$ had moderate to severe fibrosis, with compromised the spermatic quality. Conversely, when evaluating bulls of 18 - 20 months of age $(n=105)$, the authors observed no association between the severity of fibrotic lesions and seminal characteristics.

Chapwanya et al. [17] and Gnemmi and Lefebvre [18] also identified palpable and non-palpable lesions, indicating that testicular ultrasound is a more sensitive and reliable mode of diagnosis than palpation alone, whereas Chapwanya et al. [17], studying 32 bulls with an average age of 5.6 years, identified seven bulls with testicular lesions detected by ultrasonography, with two of them having levels of testicular fibrosis that could compromise seminal quality.

The degree of severity of fibrotic lesions measured in the testicles of the animals evaluated in this present study was not associated with low quality semen. Likewise, Barth et al. [16] noted that even bulls with very severe degrees of fibrosis produced semen with up to $94 \%$ morphologically normal spermatozoa. These results indicate that the presence of relatively large amounts of scar tissue within the testicular parenchyma does not necessarily prevent the production of normal spermatozoa by other areas of the testicular parenchyma. According to the authors, large amounts of scar tissue would be needed to reduce spermatic production.

The present study showed that $85 \%$ of animals were able to reproduction, while $15 \%$ were unable to reproduction. However, no difference was found in the IP between the testicles, or between the classes of rams able and unable to reproduction $(\mathrm{P}>0.05)$, corroborating the results of the studies by Aravindakshan et al. [12] and Cardilli et al. [19], which found no differences in the IP for the left and right testicles of bovines.

The observed differences $(\mathrm{P}<0.05)$ in physical semen parameters (motility and vigor) between the classes were expected, since the spermatic morphology was the main criterion used for and urological classification, and since the rams 
were classified as unable only by spermiogram and not by any other reproductive clinical findings.

Further, in the present study, the SC and BCS did not present significant differences $(P>0.05)$ between able and unable classes, with average values of 28.6 $\mathrm{cm}$ and 3.51 for animals able to reproducing, and $27.7 \mathrm{~cm}$ and 3.34 for animals unable to reproduction, respectively. Although a difference in SC in relation to the and urological classes studied was not observed $(\mathrm{P}>0.05)$, according to Guimarães et al. [20], breeding animals with elevated SC are more likely to present satisfactory BSE in relation to those with lower SC. However, this fact has low correlation in adult animals, being high only in growing animals.

The existence of a correlation between SC and reproductive characteristics in ovines, confirmed by Land [21], and later by Notter et al. [22], may be considered when choosing the breeding animal. This assertion corroborates the findings of Moraes et al. [23], when evaluating the fertility of ovines of the Corriedale breed, aged from 12 to 24 months, and using a SC greater than $29 \mathrm{~cm}$ as the reference. The authors concluded that there exists a margin of security of $90 \%$ in choosing rams based on this characteristic.

According to Cardoso and Queiroz [24], SC also provides a substantial amount of information on the reproductive capacity of ovines, emphasizing its importance within the testicular morphometry and its usefulness as a component in the selection of rams.

Freitas et al. [25] evaluated hair ovines of Santa Inês, Somali, and Morada Nova breeds, from 6 to 36 months of age, with the SC ranging from 24 to $33 \mathrm{~cm}$, and concluded that this parameter is related to the weight and age of the animals, and that those that do not present the expected SC for their reproductive age should be discarded. Furthermore, Souza and Costa [26] noted in hair ovines of mixed breed, with an average SC of $24.4 \mathrm{~cm}$, a high correlation between this parameter and body weight, concluding that the choice of the ram can be made based on one of these parameters.

Moreover, in studies with ovines of the Hampshire Down breed and their crosses, Mies Filho et al. [27] observed that all the pure-bred lambs presented spermatozoa at six months of age, always being heavier and with an SC of about $26.0 \mathrm{~cm}$, which did not occur with the mixed breeds, although spermatozoa were found in such animals with a scrotal circumference of at least $27.0 \mathrm{~cm}$; spermatogenesis really established itself when the animals presented a scrotal circumference of $28.0 \mathrm{~cm}$.

\section{Conclusion}

In conclusion, the smallest representative area to evaluate the echo texture of the testicular parenchyma of ovines was found to be $1600 \mathrm{~mm}^{2}$, and there were no correlations between the intensity of pixels of the testicular parenchyma and fibrosis score with the physical and morphological characteristics of the ejaculate of the rams. 


\section{Conflict of Interests}

The authors declare that have no conflict of interests.

\section{References}

[1] King, A.M. (2006) Development, Advances and Applications of Diagnostic Ultrasound in Animals. The Veterinary Journal, 171, 408-420.

https://doi.org/10.1016/j.tvjl.2004.10.014

[2] Ginther, O.J. (1986) Ultrasonic Imaging and Reproductive Events in the Mare. 3rd Edition, University of Wisconsin, Madison.

[3] Singh, J., Pierson, R.A. and Adams, G.P. (1998) Ultrasound Image Attributes of Bovine Ovarian Follicles and Endocrine and Functional Correlates. Journal of Reproduction and Fertility, 12, 19-29.

http://www.reproduction-online.org/content/112/1/19.long https://doi.org/10.1530/jrf.0.1120019

[4] Pierson, R.A. and Adams, G.P. (1995) Computer-Assisted Image Analysis, Diagnostic Ultrasonography and Ovulation Induction: Strange Bedfellows. Theriogenology, 43, 105-112. https://doi.org/10.1016/0093-691X(94)00014-L

[5] Singh, J., Adams, G.P. and Pierson, R.A. (2003) Promise of New Imaging Technologies for Assessing Ovarian Function. Animal Reproduction Science, 78, 371-399. https://doi.org/10.1016/S0378-4320(03)00100-3

[6] Jefferies, W.M. (1961) Occult Hypothyroidism and Metabolic Insufficiency. Journal of Chronic Diseases, 4, 582-592. https://doi.org/10.1016/0021-9681(61)90022-4

[7] Pinho, R.O., Costa, D.S., Siqueira, J.B., Martins, L.F., Miranda Neto, T., Pereira, J.V.T.N., Guimarães, S.E.F. and Guimarães, J.D. (2013) Testicular Fibrotic Lesions and Semen Quality in Adult Montana Tropical Compound bulls. Revista Brasileira de Medicina Veterinaria, 35, 105-110. http://rbmv.org/index.php/BJVM/article/view/602/466

[8] CBRA-Colégio Brasileiro de Reprodução Animal (2013) Manual for Breeding Soundness Examination. 3rd Edition, Belo Horizonte.

[9] Jucá, A.F., Pinto, L.F.B., Moita, A.K.F., Oliveira, R.J.F., Melo Filho, G.M., Santos, L.B., Fiuza, M.S. and Azevedo, H.C. (2011) Testicular Ecotexture by Ultrasonography in Santa Inês Rams. Proceedings of XXI Congresso Brasileiro de Zootecnia, Maceió, 23-27 May 2011, 1-3.

[10] Andrade, A.K.G., Soares, A.T., Cartaxo, F.Q., Peña-Alfaro, C.E. and Guerra, M.M.P. (2012) Ultrasonographic Findings in the Testis and Epididymis of Clinically Healthy Young Hair Sheep. Arquivo Brasileiro de Medicina Veterinária e Zootecnia, 64, 371-379. https://doi.org/10.1590/S0102-09352012000200017

[11] Cartee, R.E., Rumph, P.F., Abuzaid, S. and Carson, R. (1990) Ultrasonographic Examination and Measurement of Ram Testicles. Theriogenology, 33, 867-875. https://doi.org/10.1016/0093-691X(90)90822-B

[12] Moura, J.C.A., Jucá, A.F., Gusmão, A.L., Bittencourt, T., Pinho, T.G. and Barbosa, C.M.P. (2008) Testicular Ecotexture of the Santa Inês Rams. A Hora Veterinária, 27, 9-22.

[13] Aravindakshan, J.P., Honaramooz, A., Bartlewski, P.M., Beard, A.P., Pierson, R.A. and Rawlings, N.C. (2000) Pattern of Gonadotropin Secretion and Ultrasonographic Evaluation of Developmental Changes in the Testis of Early and Late Maturing Bull Calves. Theriogenology, 54, 339-354. 
https://doi.org/10.1016/S0093-691X(00)00353-8

[14] Hamm, B. and Fobbe, F. (1995) Maturation of the Testis: Ultrasound Evaluation. Ultrasound in Medicine and Biology, 21, 143-147. https://doi.org/10.1016/S0301-5629(94)00088-3

[15] Arteaga, A.A., Barth, A.D. and Brito, L.F. (2005) Relationship between Semen Quality and Pixel-Intensity of Testicular Ultrasonograms after Scrotal Insulation in Beef Bulls. Theriogenology, 64, 408-415. https://doi.org/10.1016/j.theriogenology.2004.12.008

[16] Barth, A.D., Alisio, L., Avilés, M., Arteaga, A.A., Campbell, J.R. and Hendrick, S.H. (2008) Fibrotic Lesions in the Testis of Bulls and Relationship to Semen Quality. Animal Reproduction Science, 106, 274-288. https://doi.org/10.1016/j.anireprosci.2007.05.002

[17] Chapwanya, A., Callanan, J., Larkin, H., Keenan, L. and Vaughan, L. (2008) Breeding Soundness Evaluation of Bulls by Semen Analysis, Testicular Fine Needle Aspiration Cytology and Trans-Scrotal Ultrasonography. Irish Veterinary Journal, 61, 315-318.

https://www.ncbi.nlm.nih.gov/pmc/articles/PMC3113862/pdf/2046-0481-61-5-315. pdf

[18] Gnemmi, G. and Lefebvre, R.C. (2009) Ultrasound Imaging of the Bull Reproductive Tract: An Important Field of Expertise for Veterinarians. Veterinary Clinics of North America: Food Animal Practice, 25, 767-779. https://doi.org/10.1016/j.cvfa.2009.07.006

[19] Cardilli, D.J., Toniollo, G.H., Pastore, A.A., Canola, C.J. and Mercadante, M.E.Z. (2009) Ultrasonographic Changes of the Testicular Parenchyma Pattern in Young Nelore Bulls. Acta Scientiae Veterinariae, 37, 367-370. http://www.ufrgs.br/actavet/37-4/Art\%20858.pdf

[20] Guimarães, J.D., Vasconcelos, C.O., Guimarães, S.E.F., Costa, E.P. and Miranda Neto, T. (2003) Testicular Biometry in Nellore Bulls, from 20 to 22 Months of Age. Revista Brasileirade Reprodução Animal, 27, 173-174.

[21] Land, R.B. (1973) The Expression of Female Sex-Limited Characters in the Male. Nature, 241, 208-209. https://www.nature.com/articles/241208a0

[22] Notter, D.R., Lucas, J.R. and McClaugherty, F.S. (1981) Accuracy of Estimation of Testis Weight from in Situ Testis Measures in Ram Lambs. Theriogenology, 15, 227-234. https://doi.org/10.1016/S0093-691X(81)80011-8

[23] Moraes, J.C.F., Silva, J.F. and Ferreira, J.M.M. (1985) Seasonal Variation of the Scrotal Perimeter in Corriedale Lambs. Proceedings of VI Simpósio Nacional de Reprodução Animal, Belo Horizonte, 15-19 July 985, 423-424.

[24] Cardoso, F.M. and Queiroz, G.F. (1988) Duration of the Cycle of the Seminiferous Epithelium and Daily Sperm Production of Brazilian Hairy Rams. Animal Reproduction Science, 17, 77-84. https://doi.org/10.1016/0378-4320(88)90047-4

[25] Freitas, V.J.F., Lima, F.R.G. and Paiva, H.M. (1991) Testicular Biometry of Goats and Sheep Raised in the State of Ceará. Revista Ciencia Animal, 1, 51-63.

[26] Souza, I.A.T. and Costa, F.A.L. (1992) Semen Characteristics and Correlation with Other Reproductive Parameters in Rams. Proceedings of V Simpósio em Ciências Agrárias, Teresina, 2-5 July 1992, 80-86.

[27] Mies Filho, A., Jobim, M.I.M., Oberst, E.R. and Wald, V.B. (1993) Seasonal Variation of Sperm Production and Scrotal Perimeter of Hampshire down Rams. A Hora Veterinária, 13, 53-57. 